\title{
DORSO-LUMBAR SPINE FRACTURES: RECUMBENT vS. OPERATIVE TREATMENT
}

\author{
RAe R. JaCobs, M.D., F.A.C.S., ${ }^{1}$ Marc A. Asher, M.D., ${ }^{2}$ and \\ ROBERT K. SNIDER, M.D. ${ }^{3}$ \\ ${ }^{1}$ Orthopedic Section, Veterans Administration Medical Center, Kansas City, Missouri, \\ Problem Spine Clinic, Kansas University Medical Center; ${ }^{2}$ Paraplegia Clinic, Kansas \\ University Medical Center, Kansas City, Kansas, ${ }^{3}$ St Vincent Hospital, Billings, Montana.
}

\begin{abstract}
Internal fixation of fractures of the dorsal-lumbar spine with early ambulation is evaluated in this study of 100 patients with I06 fractures: 34 being treated by recumbency, I 3 with Meurig-Williams plates, and 59 with Harrington rods. Fracture reduction in the recumbent group was 14 per cent unsatisfactory, 82 per cent satisfactory, and only one case anatomical. Following plating, 38 per cent were unsatisfactory and 6I per cent satisfactory. Harrington rod reduction and internal fixation resulted in 67 per cent anatomical, 3I per cent satisfactory, and 2 per cent unsatisfactory. Neurologic improvement in partial lesions was 53 per cent with Harrington rods and 44 per cent with recumbent treatment. For paraplegic patients the time required for wheelchair ambulation was reduced from 10.5 weeks with recumbent treatment to 5.3 weeks with Harrington instrumentation. Ambulatory candidate rehabilitation time was decreased from $7 \cdot$ I weeks to 2.5 weeks. Complications were reduced from I8 per cent in the recumbent group to 7 per cent in the Harrington rod group. By using the three above-three below, rod long-fuse short approach rather than the two above-two below with fusion over the length of the rods technique, the number of anatomical reductions was increased from 70 per cent to 82 per cent and the length of the fusion decreased from 4.8 levels to $\mathrm{I} \cdot 4$ levels.
\end{abstract}

Key words: Spinal injuries; Internal fixation.

\section{Introduction}

Although non-operative treatment of dorso-lumbar spine injuries has been the standard around the world, surgery offers two major advantages. The first is decompression of the neurologic structures with possible greater neurologic recovery in partial lesions. The historical approach has been laminectomy. This procedure provides posterior decompression only when more frequently the offending lesion is a bone fragment anteriorly, from a vertebral body fracture. In addition, due to flexion angulation the neurologic structures are stretched over the anterior deformity. Excision of posterior ligamentous structures in association with laminectomy contributes to spinal instability. It is more appropriate to obtain neurologic decompression by reduction of the fracture dislocation.

Although fair alignment of angular deformity can be easily obtained by closed methods, open reduction allows anatomical correction of both angular and translational deformity. Also, any remaining fragments of bone or disc material in the canal can be removed through a postero-lateral approach. The instrumentation used for reduction of the injury should also provide sufficient stability for immediate ambulation-the second advantage of surgical management. The

Acknowledgement. A few of these cases were contributed by members of the adjunct faculty of Kansas University Medical Center. 
pulmonary, vascular, urologic, and psychologic complications of prolonged recumbency are prevented, as well as months of wasted time (Jacobs, I980). The problem of progressive deformity with neurologic deficit is also avoided.

\section{Case Material}

Early neurologic decompression and spinal stabilisation is evaluated by this comparative study of IO6 fractures of the dorsal-lumbar spine in Io0 patients followed over one year. Thirty-two patients were treated with varying periods of recumbency followed by external immobilisation. Thirteen were treated with Meurig-Williams spinous process plates. Harrington rods were used in the remaining 55 cases. The injuries were similarly distributed throughout the thoraco-lumbar spine regardless of the treatment method, Table I. The 58 fractures associated with 'paraplegia' are those in which there was no useful motor function below the level of the lesion. The 48 'ambulatory' category injuries are those associated with at least some useful motor function below the lesion. The proportion of 'paraplegic' cases is nearly the same in each treatment group.

All cases included in this study were considered to be 'unstable'. Our understanding of this term is somewhat different from that proposed by Holdsworth (1970). First, any injury of the dorsal-lumbar spine sufficiently severe to be associated with a neurologic deficit is assumed to be mechanically unsound for early ambulatory treatment without internal fixation. Second, injuries that may result in neurologic damage are also considered unstable. A vertebral body fracture where the fragments might become displaced into the canal with the early ambulatory treatment should be stabilised to prevent neurologic injury. If there is evidence of posterior ligamentous disruption on physical examination and/or on X-ray, this is also an indication of instability because neurologic damage may result from increasing flexion deformity. Rotational instability can likewise lead to neurologic damage, but in most cases this is present initially.

The third indication is an injury which may lead to 'chronic instability'. Although there may not be any neurologic damage initially nor any likely to occur in the immediate post-injury period, it may develop late due to progressive deformity. The so-called stable compression fracture is frequently in this category, and as pointed out by Nash, may develop neurologic deficit (Nash et al., 1977). In addition, any vertebral body compression fracture involving a loss of anterior vertebral height of over 50 per cent has a high likelihood for late mechanical instability. Back pain may develop at the site of injury or inferior to the resulting gibbus due to a compensatory lordosis. Soreff reviewed 147 compression fractures more than eight years post-injury, and found the objective physical and radiologic abnormalities correlated with symptoms and disability (Soreff, 1977). Injuries in the thoraco-lumbar, and especially the lumbar, spine led to greater disability than in the thoracic area. In addition, neurologic deficit may result from late progressive deformity. All these problems can be avoided by correction of the deformity and stabilisation at the time of injury. Late treatment of these problems is far more difficult.

\section{Treatment Methods}

All patients in the recumbent group were treated either on a frame or an ordinary hospital bed. Marked deformity was reduced and controlled by closed methods. Patients were then mobilised in an orthosis or a plaster cast. The majority, but not all, of these cases were treated earlier in the study and on the rehabilitation service. An example of our unsatisfactory results with recumbent treatment is a I5-year-old female who sustained a fracture dislocation of L2 with partial neurologic deficit following an automobile accident. A three-level wide laminectomy was performed. Spine fusion was not attempted because the orthopaedist felt that there was inadequate bone remaining. The patient was treated recumbently for 3 months, resulting in a fibrous union. Nine years later a minor automobile accident led to permanent paraplegia and this deformity (Fig. I). 


\section{TABLE I}

The injuries were distributed throughout the thoraco-lumbar spine with concentration at the thoraco-lumbar junction in all three treatment groups. Fractures associated with little or no useful motor function below the area of injury were considered paraplegic and represented about 55 per cent of the cases, whereas ambulatory patients are those who had either normal of definitely useable motor function below the level of injury and represented the remaining 45 per cent.

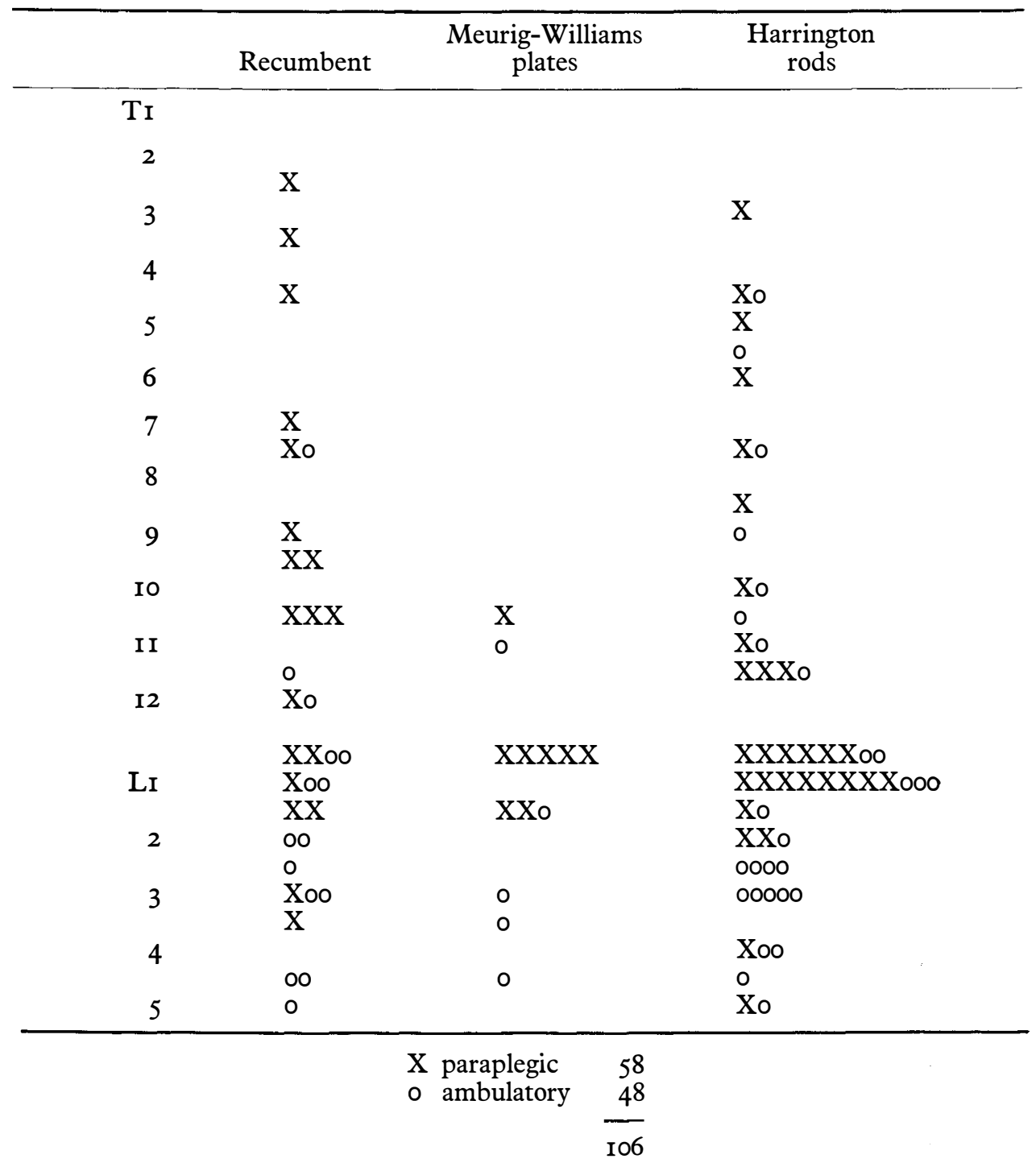

During the late I960s, open reduction of spinal injuries with stabilisation by Meurig-Williams plates was attempted. Rotational instability was sufficiently controlled to allow safer nursing care in an ordinary hospital bed, but attempts at early ambulation with plaster casts were all too often not successful. This 35- 

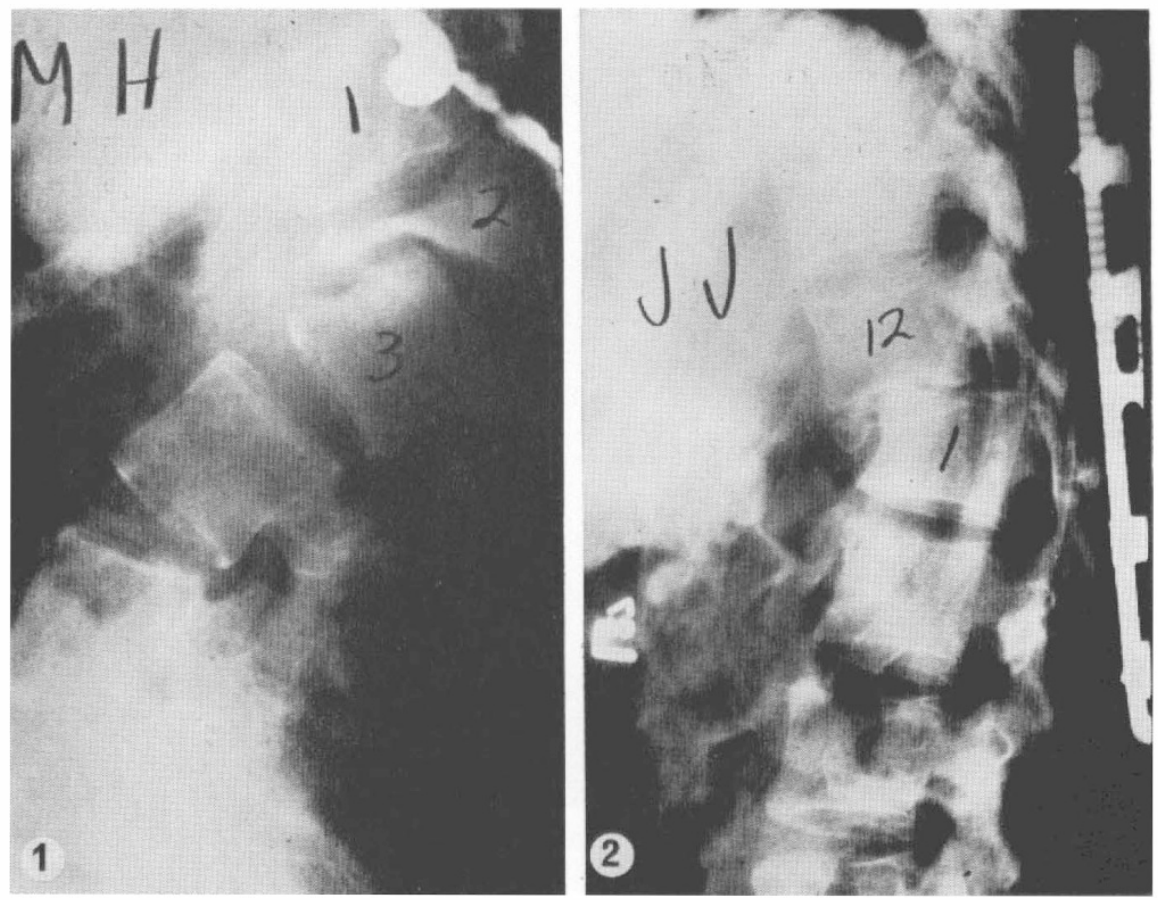

FIG. I

Late deformity and an increase in neurologic deficit are all too often the result of recumbent treatment. A minor automobile accident led to permanent paraplegia associated with this deformity after a fracture dislocation 9 years previously which had been treated by recumbent therapy following laminectomy.

FIG. 2

Attempts at spinal stabilisation with spinous process plates also do not allow early mobilisation. This fracture dislocation with paraplegia was 'stabilised' with plates but displaced after wheelchair ambulation Io weeks post-injury.

year-old man was run over by a truck, sustaining a fracture dislocation of TI2-LI with total paraplegia (Fig. 2). Open reduction and internal fixation with plates was performed; but after ten weeks, when the patient was allowed up in a wheelchair, the reduction was lost and the plates protruded painfully.

A 47-year-old diabetic was involved in a collision when she lost consciousness secondary to a hypoglycaemic episode. She sustained this burst fracture of $\mathrm{L}_{3}$ with loss of all ankle motion and some weakness of the quadriceps bilaterally (Fig. 3, A and B). Within 24 hours, an open reduction with bilateral Harrington distraction rods was performed from $\mathrm{LI}_{-} \mathrm{L}_{5}$. Because of posterior ligamentous disruption across the area of injury, a fusion was performed from L2-L4. The patient was ambulated in a Jewett brace 2 weeks post-surgery. By 6 weeks the neurologic deficit had cleared. One year following surgery the rods were removed and the fusion found to be solid. Three months later flexion films demonstrated maintenance of the reduction and an increase in flexibility of the spine.

This I7-year-old male was involved in an automobile accident leading to paraplegia with slight sacral sparing due to a burst fracture of $\mathrm{L}_{4}$ (Fig. 4). Open reduction and internal fixation with distraction rods was performed without 


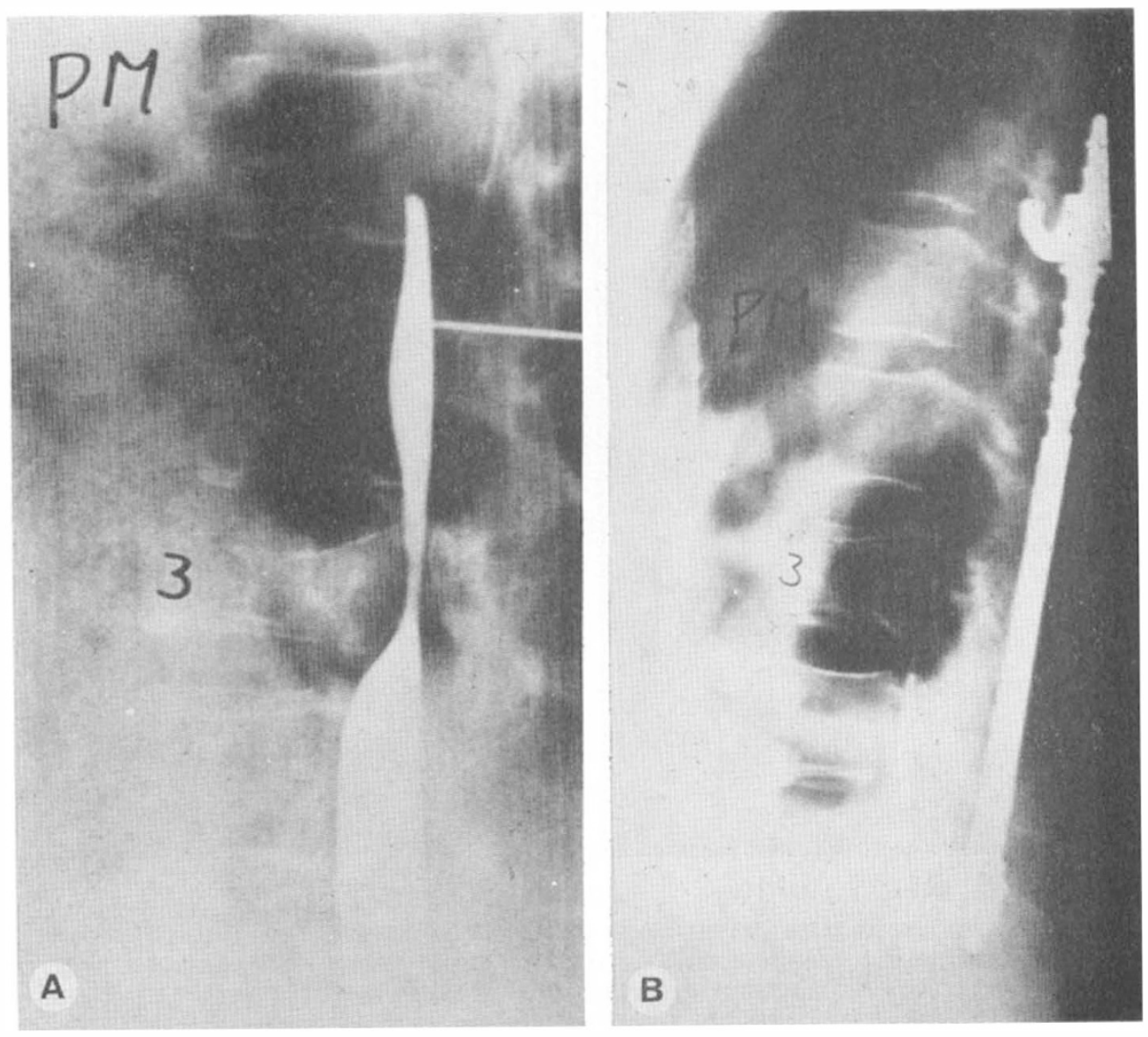

FIG. 3, A and B

A 47-year-old female diabetic sustained this burst fracture of $\mathrm{L}_{3}$ with loss of plantar and dorsi flexion of the ankles and some weakness of the quadriceps bilaterally. The fracture was reduced with Harrington rods, and because of posterior ligamentous disruption, a fusion was performed across the area of injury.

laminectomy or fusion. Note that the rods are contoured to the normal lumbar lordosis, providing contact with the lamina adjacent to the area of fracture. With lower lumbar fractures, the lower hook must rest on the sacral ala as the Si lamina does not have sufficient strength to withstand the high stresses. In addition, square-ended rods which insert into square holes in the inferior hooks are necessary to maintain the rods in the proper position when they are contoured in this manner.

\section{Results}

The first reason for considering surgical treatment was neurologic decompression. Neurologic improvement was evaluated by assigning the numbers one through five to the Frankel classes A through E, respectively (Frankel, 1969). The observed increase, that is the observed minus the initial value, was divided by the maximum improvement possible, that is five minus the initial value. This gives a per cent recovery. For a Frankel $\mathrm{B}$ that improved to a $\mathrm{D}$, the per cent recovery would be $(4-2) /(5-2)=66.7$ per cent. As the $E$ group could not improve and none of the A group cases did improve, only the $\mathrm{B}, \mathrm{C}$ and $\mathrm{D}$ or partial lesion 


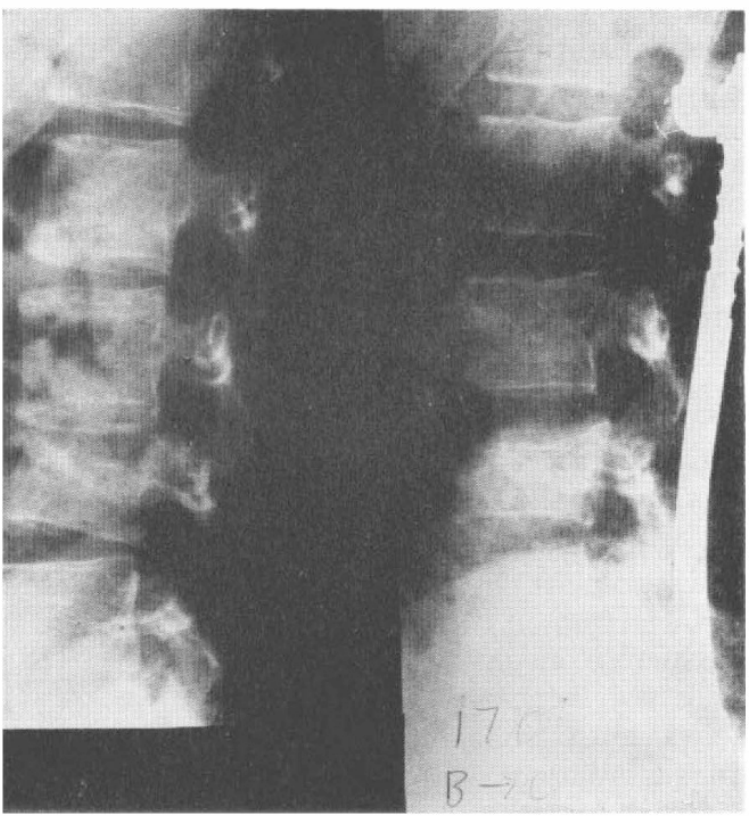

FIG. 4

This I7-year-old male sustained a burst fracture of $\mathrm{L}_{4}$ associated with slight sacral sparing. An open reduction and internal fixation with distraction rods was performed with the inferior hooks on the sacral alae. Note that the rods are contoured both anteriorly into the normal lordotic curve and toward the midline so as to apply anterior pressure on the lamina of $\mathrm{L} 4$.

cases were considered. In no case did the neurologic function decrease. Laminectomy appeared to have no beneficial effect (Table 2). Neurologic improvement with rods was somewhat better, rather than worse, when compared with recumbent treatment ( 53 per cent compared with 44 per cent). The group treated with plates is too small to be considered.

\section{TABLE II}

Neurologic status was evaluated using the Frankel classification ( $\mathrm{A}=$ paraplegia, $\mathrm{B}=$ sensation only, $\mathrm{C}=$ motor useless, $\mathrm{D}=$ motor useful, $\mathrm{E}=$ normal), assigning the numbers one through five to the worst through the best categories. The observed neurologic improvement was divided by the maximum possible neurologic improvement giving the per cent recovery. The neurologic recovery in the Harrington rod group was 53 per cent compared with only 44 per cent in the recumbent treated group.

\begin{tabular}{lcccc}
\hline & \multicolumn{4}{c}{ Neurologic improvement } \\
\cline { 2 - 5 } & Recumbent & $\begin{array}{c}\text { Meurig-Williams } \\
\text { plates }\end{array}$ & $\begin{array}{c}\text { Harrington } \\
\text { rods }\end{array}$ & Total \\
\hline Laminectomy & $43 \%$ & $0 \%$ & $53 \%$ & $50 \%$ \\
No laminectomy & $46 \%$ & $57 \%$ & $53 \%$ & $5 \mathrm{I} \%$ \\
Both & $44 \%$ & $50 \%$ & $53 \%$ & $5 \mathrm{I} \%$ \\
\hline
\end{tabular}


The anatomical results were measured on AP and lateral X-rays. Less than Io per cent displacement and I 5 degrees of angulation in both views was considered anatomical. Over 50 per cent displacement or 45 degrees of angulation in either view was considered unsatisfactory. All other cases were considered satisfactory. In the recumbent group 82 per cent of the cases were satisfactory and I 4 per cent unsatisfactory, with only one case anatomical (Table 3). With the use of spinous process plates the anatomical results were worse, possibly due to the injury of muscles and ligaments by surgery, combined with the relatively poor fixation obtained. In contrast, open reduction and internal fixation with Harrington rods resulted in two-thirds of the cases being anatomically reduced in both the paraplegic and ambulatory groups.

The effect of treatment on rehabilitation was evaluated by determining the number of weeks required for paraplegic patients to be up in wheelchairs performing independent transfers, and for ambulatory candidates to be walking (Table 4). The use of Meurig-Williams plates had no effect on rehabilitation of paraplegic patients, but there was some slight decrease in the time required in the ambulatory group. In contrast, Harrington rod treatment allowed wheelchair use in half the time in paraplegic patients. Even greater improvement occurred in the ambulatory patients-walking in 2.5 weeks compared with 7.1 weeks. Thus, the overall rehabilitation time was cut from 9 weeks to 4 weeks. Rehabilitation of paraplegic patients was evaluated more completely by a modified self-care score studying feeding, personal hygiene, moving in bed, dressing, bowel and bladder care, transfers, and locomotion (Table 5), (Kelly \& Rose, I97I). At 4 weeks the scores were similar in both the recumbent and operative group. At 8 weeks the operative group scores were nearly twice that of the recumbent group, I5.94 versus 8.87 . By I 3 weeks the operative group achieved a plateau, I9.69, whereas 20 weeks were required for the recumbently treated group to reach a plateau of I6.69. Thus

\section{TABLE III}

The fracture reduction was evaluated radiographically on AP and lateral films. Less than 15 degrees of angulation and Io per cent displacement on both views was considered an anatomical reduction, whereas over 45 degrees of angulation or 50 per cent of displacement on either view was considered unsatisfactory. The remaining cases were considered satsifactory. Fourteen per cent of the recumbent treated cases were considered unsatisfactory and only one was anatomically reduced. With Meurig-Williams plates the results were worse, possibly due to musculoligamentous injury during surgery. In contrast with Harrington rods over two-thirds of the cases had anatomical reductions.

\begin{tabular}{llll}
\hline & \multicolumn{3}{c}{ Radiographic evaluation } \\
\cline { 2 - 4 } & Recumbent & $\begin{array}{c}\text { Meurig-Williams } \\
\text { plates }\end{array}$ & $\begin{array}{c}\text { Harrington } \\
\text { rods }\end{array}$ \\
\hline Unsatisfactory & $\frac{5}{34}=\mathrm{I} 4 \%$ & $\frac{5}{\mathrm{I} 3}=38 \%$ & $\frac{\mathrm{I}}{5 \mathrm{I}}=2 \%$ \\
Satisfactory & $\frac{28}{34}=82 \%$ & $\frac{8}{\mathrm{I} 3}=6 \mathrm{r} \%$ & $\frac{\mathrm{I} 6}{5 \mathrm{I}}=3 \mathrm{I} \%$ \\
Anatomical & $\frac{\mathrm{I}}{34}=2 \%$ & $\frac{\mathrm{O}}{\mathrm{I} 3}=0 \%$ & $\frac{34}{5 \mathrm{I}}=67 \%$ \\
\hline
\end{tabular}




\section{TABLE IV}

Rehabilitation was evaluated by determining the time required for paraplegic patients to perform independent wheelchair transfers. This period was reduced from 10.5 weeks to 5.3 weeks with Harrington instrumentation. In the ambulatory group the figure was reduced from $7 \cdot 1$ weeks to 2.5 weeks. Thus, the overall rehabilitation time was decreased to one-half.

\begin{tabular}{lccc}
\hline & \multicolumn{3}{c}{ Rehabilitation } \\
\cline { 2 - 4 } & Recumbent & $\begin{array}{c}\text { Meurig-Williams } \\
\text { plates }\end{array}$ & $\begin{array}{c}\text { Harrington } \\
\text { rods }\end{array}$ \\
\hline Paraplegic & $\mathrm{IO} \cdot 5 \pm 0.9$ & $\mathrm{I0} \cdot 0 \pm 0.5$ & $5 \cdot 3 \pm 0.6$ \\
Ambulatory & $7 \cdot \mathrm{I} \pm \mathrm{I} \cdot 3$ & $5 \cdot 4 \pm 2 \cdot 4$ & $2 \cdot 5 \pm 0.3$ \\
Total & $9 \cdot \mathrm{I} \pm 0.8$ & $8 \cdot 2 \pm 0.8$ & $4.0 \pm 0.4$ \\
\hline
\end{tabular}

\section{TABLE V}

The modified Kenny Self-care Score shows both an earlier rise as well as higher plateaus and maximum scores in the Harrington rod group.

\begin{tabular}{lrc}
\hline & \multicolumn{2}{c}{ Kenny self-care score } \\
\cline { 2 - 3 } & \multicolumn{1}{c}{ Recumbent } & Operative \\
\hline 4 weeks & $7 \cdot 47 \pm \mathrm{I} \cdot 82$ & $8 \cdot 00 \pm 0.84$ \\
8 weeks & $8 \cdot 87 \pm 2 \cdot 3 \mathrm{I}$ & $\mathrm{I} 5 \cdot 94 \pm \mathrm{I} \cdot 92$ \\
Plateau & $\mathrm{I} 6 \cdot 69 \pm \mathrm{I} \cdot \mathrm{I} 7$ (20 wks) & $19 \cdot 69 \pm \mathrm{I} \cdot 06$ (13 wks) \\
Maximum & $\mathrm{I} 6 \cdot 73 \pm \mathrm{I} \cdot \mathrm{I} 5$ & $20 \cdot 30 \pm \mathrm{I} \cdot 02$ \\
\hline
\end{tabular}

operative stabilisation led to scores 25 per cent higher $(20 \cdot 3$ versus $16 \cdot 7)$, and achieved a plateau 50 per cent earlier (I 3 weeks versus 20 weeks).

The complication rate was 18 per cent in the 32 recumbently treated patients; consisting of two pulmonary emboli, one pneumonia, one phlebitis and two decubiti. In contrast, in the 55 cases treated with Harrington instrumentation the complication rate was 7 per cent; consisting of two pulmonary emboli-one being fatal, one resolved infection, and one failure of fixation. The fatal pulmonary embolus occurred in association with a cervical fracture dislocation requiring prior treatment. We now anticoagulate all patients unless we expect them to be ambulatory in less than a week. The infection occurred in a case treated with a sacral bar, which we no longer use. This cleared with removal of the implant. The case of failure of fixation occurred in a patient with the inferior hooks in the Si foramina who was allowed use of the overhead trapeze. Both are now avoided.

\section{Current Programme of Management}

Experience with these Ioo patients has resulted in the development of the following management programme. Patients suspected of having fractures of the dorsal or lumbar spine are moved off the ambulance stretcher onto a turning frame 
with a 'mobiliser'. This device moves under the patient atraumatically by sliding a thin endless belt under him, which is then withdrawn pulling the patient with it onto the mobiliser. Partial reduction is obtained by hypertension, avoiding direct pressure over the area of injury. In the majority of cases, a significant bony malalignment of the spinal canal is found consistent with the degree of neurologic deficit. In cases where the neurologic deficit is not explained by a bony malalignment, tomograms are indicated to visualise fragments of vertebral body displaced into the canal from a burst fracture. Only rarely is a myelogram necessary to demonstrate a soft tissue lesion responsible for a neurologic deficit. In cases where it is elected not to reduce and internally stabilise an injury, tomography and myelography are more important to prove that the fracture has been satisfactorily reduced and the case is suitable for non-operative treatment.

This 20-year-old male sustained an $\mathrm{L}_{3}$ injury with partial neurologic deficit I week prior to admission (Fig. 5, A and B), (Holdsworth, 1970). Because of improving neurologic function with satisfactory gross spinal alignment, nonoperative treatment was initially considered in spite of the fragment in the canal. However, a myelogram revealed a complete block. At surgery, reduction of the fragment required direct force in addition to Harrington rods, which were placed from $\mathrm{T}_{2} 2$ to $\mathrm{L}_{5}$ with lordotic contouring. A lateral spine film in an orthosis
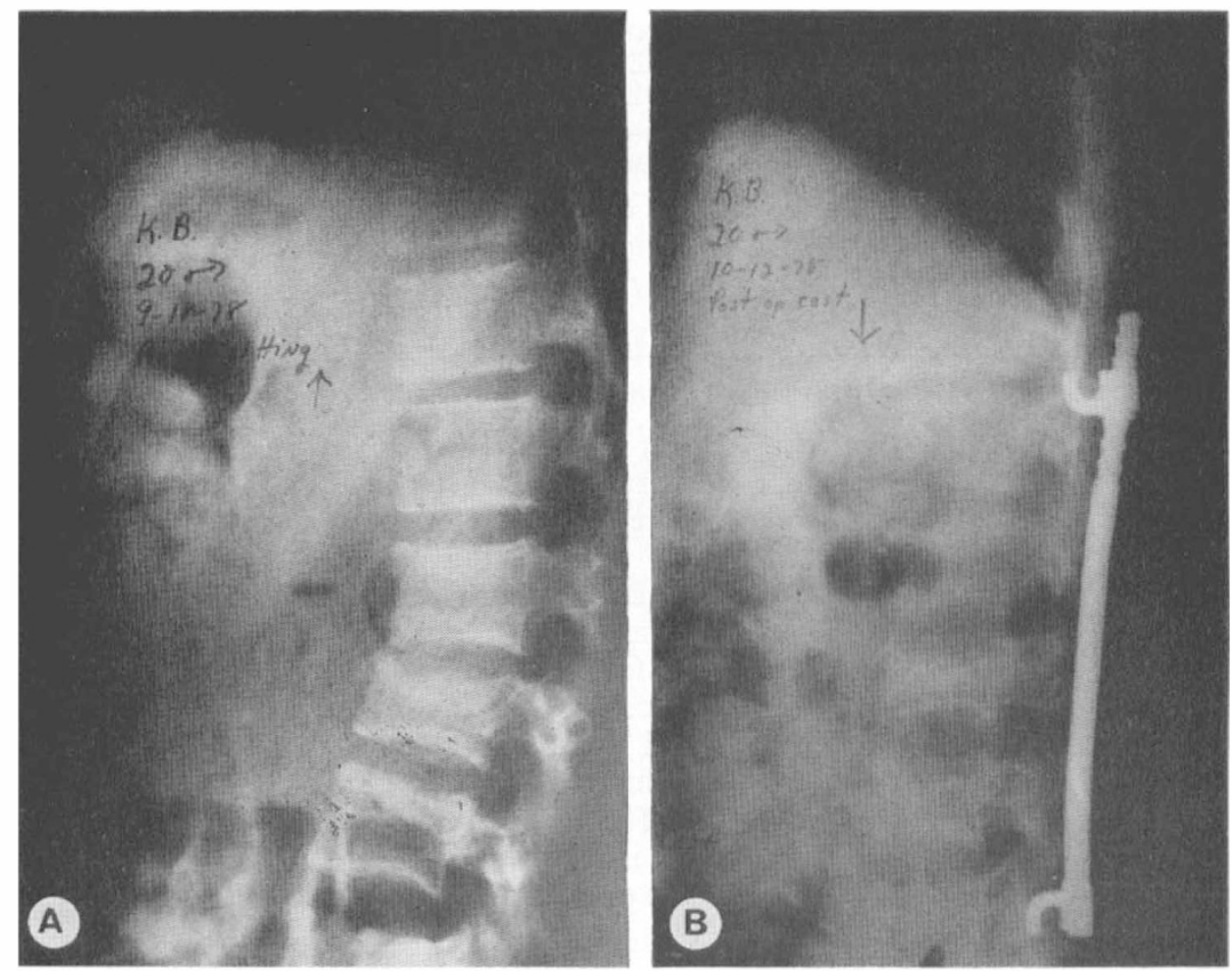

Fig. 5, A and B

A 20-year-old male sustained an $\mathrm{L}_{3}$ injury with partial neurologic deficit one week prior to admission. Because of improving neurologic function operative treatment was initially delayed in spite of the fragment in the canal. A myelogram showed a complete block indicating surgery. Immediately prior to surgery the lateral spine film still appeared to be acceptable, demonstrating its inadequacy. 
immediately prior to surgery failed to suggest this pathology. Thus, if the neurologic deficit is consistent with the displacement seen on the lateral spine film with an intact posterior body, operative reduction can be evaluated by $\mathrm{X}$-ray only. On the other hand, with significant neurologic deficit and minimal displacement laminograms usually reveal intraspinal fragments. Confidence that these are reduced requires a laminectomy for direct visualisation. Spinal cord monitoring and/or intraoperative myelography may soon make this unnecessary.

In the majority of cases operative treatment is performed electively as soon as the patient's condition is suitable. In cases with little or no neurologic deficit and where spinal malalignment has been reduced by postural means, stabilisation can be deferred. In our series, this was for an average of 5 days, but should be less. On the other hand, when spinal malalignment cannot be corrected, a partial neurologic injury involves the cord, or the deficit progresses, operative treatment should be considered as soon as possible. In our series, this was within 24 hours. Arterial and central venous lines allow monitoring of arterial and central venous pressures as well as oxygen tension.

The spine is exposed from three vertebrae above to three vertebrae below the area of injury, only to the lamina. Sharp dissection is used to avoid traumatising the neurologic structures. Hook sites are prepared at three levels above and three levels below the injured area. There must be an intact lamina two levels from the placement of each hook to provide an effective lever arm. Free fragments of lamina that might be forced into the canal are removed. If pre-operative tomograms have demonstrated fragments in the canal, laminectomy is necessary. One Harrington rod is inserted on the side opposite the greatest neurologic deficit and reduction performed. Inspection of the canal assures reduction. In only three of our cases was reduction not obtained by Harrington instrumentation alone. In these cases, the vertebral body anterior to the neurologic structures was exposed by a transpedicular approach (Flesch et al., 1977). When laminectomy is not required both rods are inserted and reduction performed. A specially designed distraction rod holder facilitates reduction greatly. In cases with significant posterior injury of the facet ligaments, posterolateral fusion is performed with iliac graft.

Following surgery the patient is transferred to a Circ-O-Lectric bed which allows rapid and safe rehabilitation. Elastic venous support as well as anticoagulation is employed. Within a week patients are moved to an ordinary bed. All patients are cautioned against attempting to sit up using an overhead trapeze as this causes very high flexion stresses on the spine. Partial lesion patients are taught to get up from the prone position. Either a spinal orthosis or, in the case of an unreliable patient, a plaster cast is used as supplemental fixation to prevent unnecessary loads on the internal fixation. A skilled spinal surgeon who understands the following mechanical principles is essential.

\section{A Biomechanical Approach}

Only by a mechanical analysis of the forces applied to the spine can one determine what structures have been injured and how their functions should be replaced by spinal instrumentation (Table 6), (Jacobs, in press). Axial distraction type of injury results in facet capsule disruption. Axial compressive loading of the spine results in vertebral body fracture. Flexion injuries result in a bending force being applied to the spine with compressive loading anteriorly and tensile 


\section{TABLE VI}

A mechanical understanding of spinal injury begins with an analysis of the forces applied and the resulting structural failure. Distraction usually produces disruption of the posterior ligamentous complex, whereas compression causes fracture of the vertebral bodies anteriorly. Flexion injuries result in varying combinations of these two components. Rotation nearly always involves facet fracture.

\begin{tabular}{lll} 
& & Mechanics \\
\hline Axial distraction & $\rightarrow$ & Facet capsule disruption \\
Axial compression & $\rightarrow$ & Body fracture \\
Flexion & $\rightarrow$ & Facet capsule disruption \pm body fracture \\
Rotation & $\rightarrow$ & Facet fracture and capsule disruption \\
\hline
\end{tabular}

loading posteriorly. The result is a combination of varying degrees of vertebral body fracture and facet capsule disruption. Rotational forces lead to disruption of the facet complex including both fracture and legamentous disruption. Most injuries involve a combination of forces. A careful history and examination usually suggests the type of force applied to the spine and the resultant structural injury. The extent of fracture can be determined by radiographs and tomograms, but posterior ligamentous injury is more difficult to detect.

Roaf, in 1960, demonstrated that all spinal injuries can be reproduced by applying various combinations of forces to the spine, such as compression, flexion, rotation and extension (Roaf, I960). He concluded that compressive forces are chiefly absorbed by the vertebral body resulting in fracture and rotational injury is the most common cause of posterior ligamentous disruption. Kelly and Whitesides point out that the anterior column structures of the spine, the vertebral bodies, are under compressive loads and the posterior structures, the ligamentous complex, are under tensile loads (Fig. 6) (Kelly \& Whitesides, I968). An understanding of this concept is basic to internal fixation of the spine. Only by analysing the injury to determine if either or both of these structures is incompetent can a suitable form of internal fixation be selected.

We have divided our cases into three biomechanical types. Distraction injuries are those in which the bony elements have a single plane fracture, or there is only ligamentous disruption resulting in a dislocation. The flexion distraction injury described by Grantham is a typical example resulting from seat-belt injuries (Grantham et al., 1976). These injuries are amenable to a posterior compression fixation device which will replace the absent posterior ligamentous structures, while the anterior bony elements will withstand the compressive loads.

Patients with complete destruction of a vertebral body and total paraplegia are also amenable to posterior compression type fixation because it is not necessary to reconstruct normal anatomy if the neurologic structures are destroyed. A compression system utilises the tension band principle with bone carrying the anterior compressive stress and the implant the posterior tensile stress, similar to a plate applied to the lateral aspect of the femur.

In burst and compression fractures the entire vertebral body is disrupted and not able to withstand any compressive loads. There is also a fracture that may best be considered a potential burst fracture in which the entire vertebral body is involved, although there may not be displacement into the spinal canal. Widening 


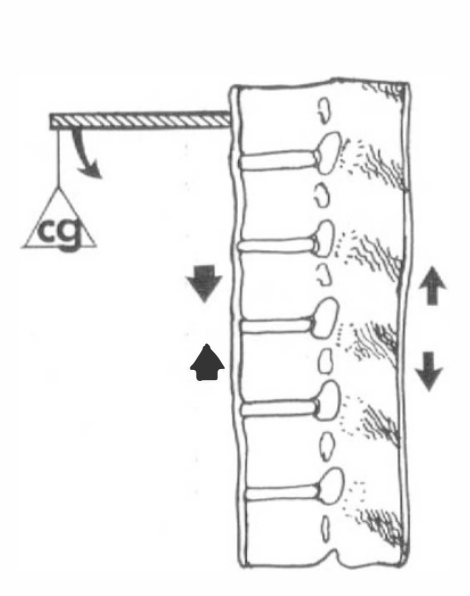

(6)

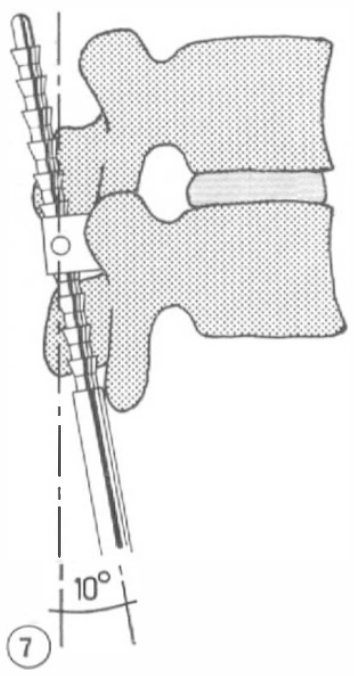

FIG. 6

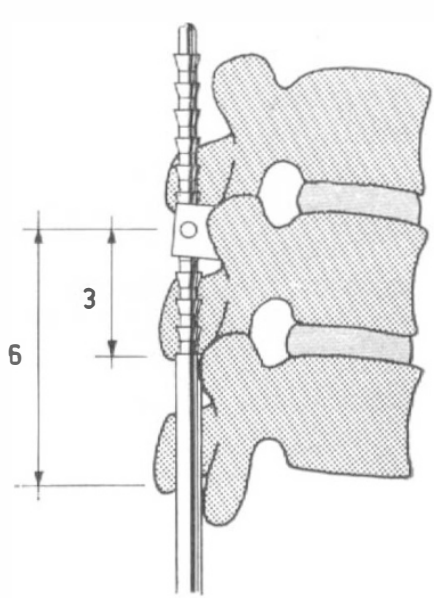

(8)

The centre of gravity is located anterior to the spine and therefore imposes a flexion load. This results in compression of the vertebral bodies which are anterior, and tension in the ligamentous complex which is posterior. This basic principle is essential to understanding the nature of an injury and the selection of a technique of stabilisation.

FIG. 7

The better control of the spinal segment on either side of the injury with the three abovethree below technique, compared with the two above-two below method, has a mechanical basis. When the rod is in contact with the lamina two vertebra away from the hook, a 4-mm gap may exist between the rod and the lamina of the vertebra adjacent to the hook due to either the notches on the rod or minimal lordosis. With the two above-two below method flexion would occur until the rod impinged on the lamina, resulting in ten degrees of angulation.

FIG. 8

Use of the longer fixation technique increases the lever arm from $3 \mathrm{~cm}$ for two vertebra to $6 \mathrm{~cm}$ for three vertebrae, thus decreasing the force applied to the bone by 50 per cent. Greater bending movements can therefore be resisted with less likelihood of fracture and hook dislodgement.

of the pedicles indicates this type of fracture, but is not always present. These fractures require a distracting device to restore vertebral height and a beam to resist bending forces, allowing correction of angulation.

The last category of injury is a fracture-dislocation, combining both an anterior bony fracture and a posterior ligamentous injury. The vertebral body can not withstand compressive loads, nor can the posterior structures withstand the tensile component of bending. These injuries also must be treated with a distracting beam to restore normal anatomy. The forces applied to the spine are resisted by the beam being stressed more in a bending mode rather than by distraction. As Stauffer emphasised, an understanding of the principle of threepoint fixation is essential to the proper use of the Harrington distraction rod in fracture treatment (Stauffer \& Neil, I975).

Rotational instability may be a component of any of the previously described injuries if the facet joints are fractured or if there is significant translational I $8 / 6-B$ 
deformity of the anterior structures. Fracture dislocations nearly always are rotationally unstable. Rotational stability can be provided by a posterior beam lying between the spinous processes medially and the facet processes laterally, extending over several vertebral levels. The distraction rod functions in this way as well as a $\frac{3}{16}$-inch compression rod with only one hook above and below. We have not used the $\frac{1}{8}$-inch rod, which requires two or three hooks above and below.

In our series of dorso-lumbar spine injuries there were three distraction injuries, nine compression injuries, 32 burst fractures and 62 fracture dislocations. As would be expected there was little neurologic deficit in the first two categories of injury, but 50 per cent of the burst fractures and two-thirds of the fracture dislocations had major neurologic involvement (Table 7).

\section{Controversies}

There is currently some controversy concerning the appropriate type of Harrington rod. In cases where the anterior bony column is intact such that compressive loads can be resisted, and where there is posterior ligamentous damage, compression rods appear to be a more satisfactory fixation device, as they replace the injured posterior ligaments. They are also appropriately used in paraplegic patients for correcting angulation without re-establishing vertebral body height. In our series we selected compression fixation in nine cases (Table 8). As is indicated by the proportion of only satisfactory reductions, this type of equipment was frequently used in paraplegic patients for correction of angulation. Distraction rods can safely be used in any case, but not compression rods. Their disadvantage is they require a larger exposure and immobilise a much longer spinal segment.

A question arises regarding the length of the rods and the indication for fusion. Should the rods be placed from two levels above to two levels below the area of injury with a fusion equal to the length of the rods, as recommended by Dickson et al. (1978); or three levels above to three levels below and no fusion, as recommended by Peterson and Armstrong (1976)? In our series, using the two above and two below method, anatomical reduction was achieved in only 70 per cent of these 20 cases. In using the three above and three below approach, with a fusion confined to the area of injury in fracture dislocation or no fusion at all in burst fracture, anatomical reduction was achieved in 82 per cent of the cases (Table 8).

This apparent better control of the spinal segments has a mechanical explanation. For the fixation device to function by resisting bending, rather than simply

\section{TABLE VII}

The distribution of injuries by type demonstrates that the majority of our cases were fracture dislocations, two-thirds of which were in the paraplegic category. About half of the burst fractures were associated with a major neurologic deficit.

\begin{tabular}{lcccc}
\hline & Distraction & Compression & Burst & $\begin{array}{c}\text { Fracture } \\
\text { dislocation }\end{array}$ \\
\hline Paraplegic & I & 0 & I7 & 40 \\
Ambulatory & 2 & 9 & I5 & 22 \\
Total & 3 & 9 & 32 & 62 \\
\hline
\end{tabular}




\section{TABLE VIII}

Compression rods did not give a high percentage of anatomical reductions because they were sometimes used in cases of total paraplegia resulting from fracture dislocation in which it was necessary only to correct angulation, and not reestablish normal vertebral body height. Initially distraction rods were used from two above to two below with fusion over the length of the rod. Now we place the rods from three above to three below with a short fusion or none, and carefully contour the rods to provide an anteriorly directed force on the laminae immediately adjacent to the fracture. This has resulted in an improvement of the number of anatomical reductions from 70 per cent to 82 per cent.

\begin{tabular}{llcc}
\hline & \multicolumn{2}{c}{ Distraction rods } \\
\cline { 3 - 4 } Compression rods & \multicolumn{1}{c}{$\begin{array}{c}\text { fusion } \\
2+2\end{array}$} & $\begin{array}{c}\text { Short fusion } \\
\text { or none } \\
3+3\end{array}$ \\
\hline Unsatisfactory & $\frac{0}{20}$ & $\frac{0}{29}$ \\
Satisfactory & $\frac{4}{9}=44 \%$ & $\frac{6}{20}=30 \%$ & $\frac{5}{29}=17 \%$ \\
Anatomical & $\frac{5}{9}=56 \%$ & $\frac{\mathrm{I} 4}{20}=70 \%$ & $\frac{24}{29}=82 \%$ \\
\hline
\end{tabular}

by distraction, necessitates accurate contouring of the rod to the normal shape of the spine in the area of injury. Use of a straight rod in the normally kyphotic upper thoracic spine will result in overcorrection, or more likely, fracture of the lamina. In the lordotic lumbar spine the rod must be curved anteriorly into the concavity. With proper contouring the mid-portion of the rod exerts an anterior force on the lamina adjacent to the injury. If the vertebra subjected to this anterior force is adjacent to the one with the hook, a mere four millimeter gap between the rod and the lamina will result in ten degrees of angulation, Figure 7. It is frequently impossible to properly contour the rod over the short distance between two adjacent vertebra to obtain an accurate reduction. In contrast, with the three above-three below method the rod can be easily contoured to obtain proper contact against the lamina. The lamina-rod error required to produce a ten degree error in reduction is nearly $\mathrm{I} \mathrm{cm}$. Also, the lamina contacts the smooth portion of the rod rather than ratchet area, thus further decreasing the error.

There is another mechanical reason for using a longer internal fixation device. The rods act as a beam subjected to three-point bending stress by the superior and inferior hooks being attached to the spine and the central portion of the rod impinging on the spine at the area of instability. Actually four-point loading is more likely with the lamina on either side of the injury forming the central points of loading. If the hook is placed into one vertebra and the rod impinges on the lamina of the adjacent vertebra as in the two above-two below technique, the lever arm length to resist the bending movement is three centimeters (Fig. 8). With the three above-three below approach the lever arm increases to $6 \mathrm{~cm}$, 
resulting in a 50 per cent decrease in the force applied to the bone by the fixation device.

We are also interested in maintaining spinal flexibility. When fusion was carried out over the length of the rods the average number of levels fused was 4.8 . In contrast, with the short fusion approach the number was $I \cdot 4$ levels (Table 9). The result is a more normally flexible spine. This latter technique requires a second procedure to remove the rods, which is performed after a minimum of a year. In all cases thus far, we have found the fusions to be solid and flexion films following the removal of the rods have demonstrated maintenance of the reduction. We have had no cases of back pain related to the hook sites or the immobilisation of the spine by the Harrington rods for the one-year period. In one case a patient failed to return for rod removal until I 8 months following injury, at which time one of the rods was broken. The patient had no symptoms referable to this.

\section{TABLE IX}

Fusion is performed for posterior ligamentous damage. In burst fractures without posterior ligamentous injury, no fusion is required. But, if vertebral body height is not re-established to at least 80 per cent of normal then angular deformity can be expected to recur with removal of the rods. To prevent this, fusion across the area of injury is also performed. Using this approach, the number of levels fused has been reduced from $4 \cdot 8$ to $\mathrm{I} \cdot 4$.

\begin{tabular}{cccc}
\hline & \multicolumn{3}{c}{ Levels fused } \\
\cline { 2 - 3 } & $=$ to rods & Short fusion or none \\
\hline$n=$ & 20 & $\mathrm{I} 6$ & $\mathrm{I} 3$ \\
$4 \cdot 80 \pm 0.29$ & $\mathrm{I} \cdot 4 \mathrm{I} \pm 0.30$ \\
\hline
\end{tabular}

\section{Discussion}

The historically accepted treatment for fractures of the dorsal and lumbar spine has been postural reduction and bed rest for 8 to I2 weeks until 'stability' develops (Frankel, 1969; Guttmann, 1969). Bedbrook shortened this period to 6 to 8 weeks in paraplegic patients (Bedbrook, 1975). Attempts at internal stabilisation have been several. Kaufer reported $2 \mathrm{I}$ cases treated with open reduction, interspinous wiring and plaster-cast immobilisation for four months with good results (Kaufer \& Hayes, I966). His type II and III injuries, 75 per cent of the cases, involved vertebral body fractures which biomechanically can not be stabilised with only posterior tension wires. The plaster cast must be the major form of immobilisation, but casts are hazardous in paraplegic patients and only control gross motion. The author stressed that an advantage of their technique over Meurig-Williams plates was a shorter fusion. Lewis and McKibbin reported 27 cases treated with Meurig-Williams plates (Lewis \& McKibbin, I974). Their results were superior to postural reduction but had a high complication rate, nine of 27 requiring plate removal for pain associated with displacement. P. H. Roberts reported similar results in a series of 28 paraplegic patients (Roberts, I969). Reporting on 25 patients with traumatic paraplegia, J. B. Roberts presented a classification of fractures into three groups: wedge compression, compression 
burst, and rotational fracture-dislocation. The first and last groups rarely fused spontaneously and had a high incidence of instability (Roberts \& Curtiss, 1970).

Another device that functions as a posterior tension band is the Weiss spring, providing dynamic compression posteriorly (Weiss \& Bentkowski, I974). Obviously this technique cannot restore normal vertebral anatomy if the vertebral body is fractured. In fact, posterior compression is quite likely to compress the fractured vertebral body further, displacing fragments into the canal, causing neurologic deficit. Furthermore, rotational stability is minimal. From a biomechanical viewpoint it should only be used for the same injuries as previously described for the compression apparatus-a relatively small portion of spinal injuries. None of these techniques really provide internal fixation and therefore have limited application.

All currently available anterior spinal instrumentation provides compression by transverse vertebral body screws attached to a vertical cable or thin threaded rod. A system is being developed using a rod of sufficient diameter to allow distraction. A disadvantage of the anterior approach for spinal injuries is the inability to evaluate posterior ligamentous damage. If present, distraction can over-distract the spine possibly causing neurologic injury. Therefore the anterior approach, although ideal for late neurologic decompression, has limited application for correction of deformity and stabilisation in acute trauma.

Reports of stabilisation of fractures of the dorso-lumbar spine with Harrington instrumentation have all shown a significant decrease in hospital morbidity and an improvement in reduction. Flesch reported on forty cases but stabilisation was quite late: 70 days in cases with only instrumentation, 56 days when stabilisation was performed subsequent to laminectomy, and 2I days when the two were combined, (Flesch et al., 1977). We do not agree with their technique of reduction by use of the scoliosis outrigger. This device applies distraction to the posterior structures without three-point fixation. The result may be over-distraction with an increase in the angular deformity and neurologic injury. Two of the four pseudarthroses developed in cases treated with a compression system. This surprising finding may be due to their use of the $\frac{1}{8}$-inch rod with small hooks which provides much less rotational stability than our technique using the $\frac{3}{16}$-inch rod with the medium size hooks. Bradford, reporting on thoracic injuries, restricted the use of the compression device to kyphotic deformity, using distraction rods for rotational instability (Bradford et al., 1977). We strongly agree with posterior reduction first and removal of anterior fragments through the posterolateral approach if required, as in only three of our cases. A formal anterolateral approach is only necessary for late cases (Riska, 1976; Whitesides \& Shah, 1976). Convery reported on 24 cases, I 7 being paraplegic (Convery et al., I978). Compression and distraction techniques were employed without regard to biomechanical principles, thus explaining their inclusive results. Dickson reported on 95 acute cases treated an average of 15.7 days post-injury (Dickson et al., 1978). Although the outrigger was inserted first, they properly emphasise reduction by three-point fixation. Although the reductions were improved, neurologic recovery was no different than with treatment by closed methods. There were six broken rods, four with pseudarthroses, and six hook displacements. We agree that operative reduction and stabilisation should be performed as soon as possible. There is no evidence that anything is gained by waiting.

In our series of I06 fractures in I00 patients, we have noted improvement in neurologic status, reduction of the angular and translocational displacement, and improved rehabilitation time by treatment with Harrington instrumentation. In 
no case was there a deterioration in neurologic status. Immediate closed reduction is followed by prompt operative reduction and stabilisation. Proper contouring of the Harrington rods is essential to obtaining an accurate reduction, a point not mentioned in any of the previous reports. In fact, Flesch describes a case requiring a lumbar osteotomy to restore the normal lordosis, but fails to describe its prevention by use of properly contoured rods (Flesch et al., 1977).

Fountain recently reported on the problem of complications with Harrington rod treatment in 52 cases: post-operative pain, progressive deformity, failure of instrumentation, infection, and alignment without reduction (Fountain et al., 1978.) We have had no problem with post-operative pain in our acute fracture series even with the use of long rods over unfused spinal segments with subsequent removal at I year. The mechanical problems of progressive deformity and alignment without decompression suggest a failure to follow biomechanical principles. Intra-operative myelography demonstrating lack of a complete block is no assurance of adequate anterior decompression. Both lateral operative radiographs and direct visualisation through a partial laminectomy demonstrated reduction in all but three cases. We had only one hook dislodgement, one broken rod in a patient lost to follow-up until i 8 months post-operative, and no pseudarthroses. The longer rod technique gives better control of the spinal segments and decreases the force on the bone at hook sites, contributing to our lack of pseudarthroses and only two instrumentation problems.

In spite of this progress in stabilisation of the acutely injured spine, there is still room for improvement. The Harrington instrumentation system was developed for correction of scoliosis by distraction. Spinal instability requires a device to resist high bending forces. Note the high incidence of rod breakage and hook dislodgement reported by Dickson et al., I978. A new system of spinal instrumentation is being developed to achieve these goals without complications.

\section{Conclusions}

I. In a review of Ioo patients with dorso-lumbar spine injuries Harrington rod stabilisation decreases the time required for paraplegic patients to use a wheelchair (from 10.5 to 5.3 weeks) and for ambulatory candidates to walk (from $7 \cdot$ I to $2 \cdot 5$ weeks).

2. Anatomical reduction was accomplished and maintained in two-thirds of the cases treated with Harrington rods, but only rarely with other methods.

3. In partial lesions neurologic function was no worse, but in fact improved53 per cent compared with 44 per cent.

4. The rod long-fuse short approach improved the reduction from 70 per cent to 82 per cent anatomical, and decreased the number of levels fused from $4 \cdot 8$ to $\mathrm{I} \cdot 4$.

5. The posterior approach allows evaluation of posterior ligamentous injury, neurologic decompression by fracture reduction, anterior decompression by the posterolateral approach, immediate stabilisation by instrumentation and permanent stabilisation by fusion.

The biomechanical approach to lumbar-dorsal spine injury analyses the force applied to the spine, the structures that have failed, and the method for immediate and permanent stabilisation (Table Io). Compression usually causes fracture of the vertebral body which can be reduced by distraction and, being cancellous bone, heals rapidly. Tension usually dislocates the posterior joints by rupturing the ligamentous complex. If the anterior bone is sufficiently intact to resist compressive loads, a compression system is suitable; otherwise, distraction rods contoured 


\section{TABLE X}

By analysing the force applied to the spine, the structural failure can be predicted and an appropriate technique of stabilisation selected. The Harrington instrumentation system can provide distraction, compression, or resist bending as desired. Fractures, if reduced, will heal; but ligamentous disruption heals poorly and requires local spinal fusion.

\begin{tabular}{llll}
\hline Force & \multicolumn{1}{c}{ Structure } & \multicolumn{2}{c}{ Stabilisation } \\
\hline $\begin{array}{l}\text { Compression } \\
\text { Tension }\end{array}$ & $\begin{array}{l}\text { Anterior bone } \\
\text { Posterior ligaments }\end{array}$ & $\begin{array}{l}\text { Immediate } \\
\text { Rotarington rods distraction }\end{array}$ & $\begin{array}{l}\text { Harrington rods compression } \\
\text { or 3-4 point bending } \\
\text { Farrington rods } 2 \text { or } 3 \text { level } \\
\text { minimum }\end{array}$ \\
\hline
\end{tabular}

to resist bending are necessary. Spinal fusion is required as ligamentous healing is not adequate. Flexion injuries result in combinations of varying degrees of these two components. Rotational injury usually fractures the facet joints. Both the $\frac{1}{4}$-inch distraction rods and the $\frac{3}{16}$-inch compression system adequately control rotational instability. Fusion is necessary, as these comminuted fractures destroy the facet joints. Only by an understanding of mechanics can a rational technique of stabilisation be applied.

\section{RÉSUMÉ}

La mobilisation précose après fixation interne dans le cas de traumatismes de la colonne lombaire est évaluée chez 100 patients et 106 fractures. 34 cas étaient traités conservativement, I 3 cas par fixation avec plaques Meurig-Williams et 59 par fixation interne avec des clous de Harrington. Par le traitement conservateur, le résultat anatomique etait satisfaisant dans $82 \%$ des cas; avec le traitement par plaque, dans $61 \%$ des cas. Par contre, le traitement par clous de Harrington améliorèrent les resultats de manière significative: $67 \%$ des cas anatomiquement, et $3 \mathrm{I} \%$ de manière satisfaisante. Le pourcentage d'amélioration neurologique se monta à $53 \%$ en comparaison avec $44 \%$ obtenus avec le traitement conservateur. La durée de l'immobilisation passe de $9, \mathrm{I}$ semaines pour le traitement conservateur à 4,0 semaines pour le même groupe. Le clou long de Harrington à rétrécissement court est meilleur que le clou court où le rétrécissement couvre toute la longueur du clou.

\section{ZUSAMMENFASSUNG}

Die frühzeitige 'Mobilisation' nach operativer Frakturenbehandlung von Verletzungen der Lendenwirbelsäule wurde bei Ioo Patienten mit I06 Frakturen untersucht: 34 mit 'konservativer' (liegender) Behandlung, 13 mit innerer Schienung mit 'Meurig-Williams'Platten und 59 mit operativer Behandlung mit 'Harrington'-Rundstäben. Bei 'liegender' Behandlung war das endgültige anatomische Resultat in $82 \%$ zufriedenstellend, mit Platten jedoch reduzierte es sich auf 6I \%. Im Gegensatz dazu verbesserten sich die Ergebnisse mit 'Harrington'-Rundstäben erheblich: Der Prozentsatz der neurologischen Verbesserung stieg ebenfalls von $44 \%$ bei 'liegender' Behandlung auf $53 \%$. Die Zeit bis zur Mobilisation des Patienten verrringerte sich von 9.I auf 4.0 Wochen. Durch Anwendung des Prinzips '3 Segmente oberhalb-3 Segmente unterhalb/langer Stab-kurze Fusion' anstelle von ' 2 Segmente oberhalb-2 Segmente unterhalb mit Fusion über die ganze Stablänge' konnte die Anzahl anatomischer Repositionen von 75 auf $82 \%$ bei gleichzeitiger Verkürzung der Fusion von 4,8 auf I,4 Segmente erhöht werden. 


\section{REFERENCES}

BedBrook, G. M. (1975). Treatment of thoracolumbar dislocation and fractures with paraplegia. Clin. Orthop., II2, 27.

BRADFORD, D. S., AKBARNIA, B. A. \& WINTER, R. B. (I 977). Surgical stabilization of fracture and fracture dislocations of the thoracic spine. Spine, 2, I85-I96.

Convery, F. R., Minteer, M. A. \& Smith, R. W. (I978). Fracture dislocation of the dorsal-lumbar spine. Spine, 3, I60-I66.

Dickson, J. H., Harrington, P. R. \& ERwin, W. D. (I978). Results of reduction and stabilization of the severely fractured thoracic and lumbar spine. F. Bone foint Surg., 60A, 799-805.

FlesCh, J. R., Leider, L. L. \& ERICKson, D. L. (I977). Harrington instrumentation and spine fusion for unstable fractures and fracture-dislocation of the thoracic and lumbar spine. F. Bone Foint Surg., 59A, I43-I53.

Fountain, S. S., Nagel, D. A. \& Jameson, R. M. (1978). Complications from Harrington distraction rod fixation of fracture dislocation of the spine. Proceedings of Societe Internationale de Chirurgie Orthopedique et de Traumatologie, Kyoto, Japan, p. I82.

Frankel, H. C. (I969). The value of postural reduction in the initial management of closed injuries of the spine with paraplegia and tetraplegia. Paraplegia, 7, 179.

Grantham, S. A., Malberg, M. I. \& SMith, D. M. (I976). Thoracolumbar spine flexiondistraction injury. Spine, I, I72-I77.

GutTMAN, L. (I969). Spinal deformities in traumatic paraplegics and tetraplegics following surgical procedures. Paraplegia, 7, 38-49.

HolDSWORTH, F. (I970). Review article: Fractures, dislocations, and fracture-dislocations of the spine. F. Bone Foint Surg., 52A, I534-I55I.

JACOBS, R. R. (I980). Complications of musculoskeletal trauma. In Chap 36, Fracture Treatment and Healing, ed. R. B. Heppenstall. Philadelphia, W. B. Sanders.

JACOBS, R. R. (I980). A biomechanical basis for treatment of unjuries of the dorsolumbar spine. In Chap I4, Osteoarthromechanics, ed. D. N. Ghista, Hemisphere McGraw Hill, I980.

KAufER, H. \& HAYeS, J. T. (I966). Lumbar fracture-dislocation. F. Bone Foint Surg., 48A, $7 \mathrm{I} 2$.

Kelly, C. R. \& Rose, D. L. (I97I). Grading the rehabilitation effort. F. Kan. Med. Soc., 72, I $54-I 56$.

Kelly, R. P. \& Whitesides, Jr., T. E. (I968). Treatment of lumbar dorsal fracturedislocations. Ann. Surg., I67, 705-7I 7 .

Lewis, J. \& McKibin, F. (I974). The treatment of unstable fracture-dislocations of the thoracolumbar spine accompanied by paraplegia. F. Bone foint Surg., 56B, 603.

NASH, Jr., C. L., SchatZinger, L. H., Brown, R. H. \& Brodkey, J. (I977). The unstable stable thoracic compression fracture. Spine, 2, 26I-265.

Peterson, E. W., ARmstrong, G. W. D. (I976). Immediate reduction and fixation of major spinal fractures and dislocations as an aid to the recovery of function. Presented at the annual meeting of Neurological Surgeons, San Francisco, California.

RISKA, E. B. (I976). Anterolateral decompression as a treatment of paraplegia following vertebral fracture in the thoracolumbar spine. Int. Orthop., I, 22-32.

Roaf, R. (I960). A study of the mechanics of spinal injuries. F. Bone foint Surg., 42B, $8 \mathrm{IO}-823$.

Roberts, J. B. \& Curtiss, P. H. (1970). Stability of the thoracic and lumbar spine in traumatic paraplegia following fracture or fracture-dislocation. F. Bone foint Surg., 52A, III 5 .

RoBERTS, P. H. (I969). Internal metallic splintage in the treatment of traumatic paraplegia. Injury. Brit. F. Accident. Surg., I, 4-I I.

SOREFF, J. (I977). Assessment of the late results of traumatic compression fractures of the thoracolumbar vertebral bodies. Karolinska Hospital, Stockholm, Sweden, 1977.

STAUFFER, E. S. \& NeIL, J. L. (1975). Biomechanical analysis of structural stability of internal fixation in fractures of the thoracolumbar spine. Clin. Orthop., 112, 159-I64.

WeISS, M. \& BENTKOWSKI, Z. (I974). Biomechanical study in dynamic spondylodesis of the spine. Clin. Orthop., 103, I99.

WhITESIDES, Jr., T. E. \& SHAH, S. G. A. (I976). On the management of unstable fractures of the thoracolumbar spine: Rationale for use of anterior decompression and fusion and posterior stabilization. Spine, $\mathbf{1}, 99-107$. 